Научная статья

УДК $122 / 129$

DOI: $10.18101 / 1994-0866-2020-4-68-77$

\title{
АКСИОЛОГИЧЕСКИЕ ПАРАДИГМЫ ИСТОРИЧЕСКОЙ ОТВЕТСТВЕННОСТИ
}

\author{
(C) Авдеева Ирина Александровна \\ кандидат философских наук, доцент, старший научный сотрудник, \\ Московский государственный университет имени М. В. Ломоносова \\ Россия, 119991, г. Москва, ГСП-1, Ломоносовский пр-т, 27/4 \\ avdeeva@rambler.ru
}

\begin{abstract}
Аннотация. В статье рассматриваются возможные парадигмы аксиологического содержания идеи исторической ответственности. Первая парадигма связана с историко-политическими исследованиями феномена травмы и вины и направлена на построение политико-правовой практики. Вторая парадигма направлена на создание принципов будущего как объект исторической ответственности. Обе парадигмы взаимосвязаны между собой и представляют разные стороны как действия, так и исследования феномена исторической ответственности. Первая возникает на базе второй и в настоящее время приобретает глобальный характер, порождая новые идеи. Первая реконструирует ценности более ситуативные и преходящие, вторая направлена на поиск более фундаментальных ценностей. В частности, одной из таких идей, появившихся на базе идеи исторической ответственности перед будущими поколениями, является идея экологической ответственности. По мнению ряда автором, эта идея сейчас является первостепенной, и имеет актуальное социальноэтическое содержание.
\end{abstract}

Ключевые слова: историческая ответственность; этика; ценности; экологическая этика; этос; социально-историческая практика; социально-этический опыт.

Благодарность. Исследование выполнено за счет гранта Российского научного фонда (проект №19-18-00421). Томский государственный университет.

\section{Для цитирования}

Авдеева И. А. Аксиологические аспекты исторической ответственности // Вестник Бурятского государственного университета. Философия. 2020. Вып. 4. С. 68-77.

Идея исторической ответственности резонансно вошла в философский дискурс во второй половине ХХ в. в связи с откликом на ряд политических событий, радикально повлиявших как на дальнейший ход истории, культуры, отразившись в общественном сознании и всех исследовательских областях, предметом которых она являлась. Эта идея стала результатом рефлексии на кризисы и исторические вызовы XX в., став своего рода ответом регулятивного характера, соединив политико-правовую, социально-историческую, культурно-антропологическую и этико-аксиологическую компоненты своего содержания. Впоследствии сама идея, отнюдь не потеряв своей исторической значимости, актуализировалась перед страхом новых угроз, когда прошлое отчасти осталось в прошлом, но его уроки не прошли даром, сделав человечка и социум более чувствительными к 
этой проблематике. Сегодняшний день ставит перед социумом новые задачи, связанные с новыми рисками.

Мы часто говорим об идеологическом, политико-правовом, социальноэкономическом и даже географическом аспекте исторической ответственности, связывая ее с целым полем моральных смыслов - справедливостью, ненасилием, гуманизмом, уважением к жизни, сохранением мира и т. п., и часто делаем это тогда, когда хотим защитить некие базовые принципы социальных отношений, которые кажутся нам правильными. Так происходит процесс оценивания чего-то на пригодность основным потребностям социума и людей, его составляющих, на основе уже состоявшихся и сделанных исторических оценок. Но сама оценка события, поступка, процесса или ситуации предполагает установление связи с ценностями как критериями и основаниями оценки. Следовательно, идейный контекст исторической ответственности строится на постоянной и насущной задаче отбора, защиты и трансляции старых и поиске новых ценностных смыслов. Таким образом, сама идея исторической ответственности выступает не просто как результат исторического опыта, а результат более глубокого и онтологически ориентированного праксиологического анализа, рожденного конкретной культурой и конкретным обществом, но имеющего претензии на масштабное обобщение вследствие устойчивой связи с системой ценностных ориентаций. В этом обобщении единство метафизического и социально-этического становится отправной точкой аксиологического анализа идеи исторической ответственности. Попытка поиска основных аксиологических установок, заложенных в идее исторической ответственности, является задачей данной статьи.

Так сложилось, что политическое наполнение содержания идеи исторической ответственности зачастую превалирует над остальным содержанием, поскольку именно политический контекст имеет первостепенный практический смысл [1, с. 25]. Поэтому доминанта политического в контексте исторической ответственности (и даже совпадение исторического и политического) часто воспринимается как единственное конкретное практическое наполнение исторической ответственности как социального конструкта. Однако позволим себе с этим не согласиться, поскольку в последние несколько десятилетий собственно историческая природа этого конструкта, образовывавшая до определенного времени основную и ключевую линию в развитии идеи исторической ответственности, сменилась иной - линией ответственности не за прошлое, а за будущее. Более того, во многих современных философских программах, исследующих практические проблемы современности, преобладает позиция установления над политикоправовым полем морального. И в нем страхи перед политическими катаклизмами сменились страхами более глобального плана... Однако обе линии объединяют одно - то, что является онтологическим основанием идеи ответственности опора на более фундаментальные и общезначимые основания любого вида ответственности. По мысли Г. Йонаса, считавшего, что он нашел безусловное основание для принципа ответственности, для этого существует главная онтологическая аксиома, что само наличие целенаправленности Бытия предполагает, что бытие (как жизнь, как существование и др.) гораздо лучше небытия и что идея человеческой значимости в Бытии самой по себе есть максимальная актуализа- 
ции этой целенаправленности, что само по себе уже является этической аксиомой [2, с. 16]. Эта этическая аксиома предполагает, что существование и сущность человека никогда не определяются ставками на опасное действие, а, наоборот, отличаются стремлением к минимизации витальных рисков. И это срабатывает как прагматическое правило как для того, что имеет отношение к тем областям человеческой деятельности, где невозможно долговременное предсказание, так и для действий, где предсказание туманно и в крайне степени гипотетично. Туманность и высокая гипотетичность последних еще более усиливают чувство беспокойства, что подвигает к активизации пересмотра регулятивов.

Предположение о том, что историческая ответственность имеет разнонаправленные линии оценки социально-исторических фактов и действий на основе таких оценок, приводит нас к более широкому пониманию ответственности, где очевидной задачей становится установление той составляющей, которая бы актуализировала идею исторической ответственности в ее временном и вневременном смысле. В последнем случае она бы выступала не как конструкт для решения политических и социальных задач, а как идея, несущая в себе моральное рассуждение с целью реконструкции общезначимой аксиологической составляющей этой идеи. В таком контексте сама идея претендует на роль идентификатора более глубоких и фундаментальных внеисторических смыслов. Поиск таких смыслов, обладающих большей или меньшей значимостью, касается и индивидуального, и коллективного опыта, дополняя один другой. Осмысление опыта - дело интеллектуальных усилий следующих поколений, направленных на выживание этих поколений в социальном, политическом, культурном и, конечно, биологическом смысле. В целом смыслополагание связано с целеполаганием и является витальной необходимостью. Таким образом, задача идеи исторической ответственности состоит в определении фундаментальных значимых составляющих человеческого существования через поиск таковых в деятельности, извлечение уроков и возврат к этой деятельности на иных ценностных основаниях. И если мы придерживаемся идеи исторической ответственности как социального конструкта, то следовало бы подчеркнуть что это смысловой конструкт, содержательно (что мы ищем в опыте) и процедурно (как мы это делаем) выражающий не только наше отношение к социальной практике, но необходимость удостовериться в правильности этого отношения, верифицируя некие принципы. Ими оказываются самые глубинные принципы организации социума - основные ценностные установки, выраженные в определенных моральных оценках и императивах.

Подобная сверхзадача может осуществляться несколькими путями, которые проецируются самой идеей исторической ответственности. Один из путей актуализации ценностей, предлагаемый самой идеей, - процесс поиска идентичности, конструирование этоса как системы ценностных предпочтений, создание этикосоциальных норм. Другой путь - проецирование опыта прошлого на настоящее и будущее, выходящее за рамки ограниченного социума. Этот путь имеет куда более глобальный характер. Названные способы (отнюдь не все из возможных) отсылают нас к двум различным парадигмам исторической ответственности. Они выделяются с определенной долей теоретической условности, однако необходи- 
мы нам для выделения как два поля ценностных смыслов, по-разному актуализирующих аксиологическую проблематику.

Первая парадигма связана с исторической ответственностью в исторической ретроспективе. Поскольку она имеет дело с событиями прошлого, реконструирование которых связано с ангажированностью этого прошлого в силу необходимости решения непосредственных политических, идеологических, социальных, экономических задач. Эта парадигма имеет по преимуществу реактивный (как реакция на некие уже произошедшие действия) характер. В ней чаще и возникает проблема вины, покаяния и наказания за действия в прошлом. Моральный характер такой парадигме дают положение жертвы, идея возмездия, воздающей справедливости, обвинений правового и морального характера, которые предъявляются вполне конкретной стороне, четко определяемой и однозначно найденной. Исследование механизмов коллективной памяти, переживания травматического опыта прошлого, виктимного статуса реабилитации, воздающего характера справедливости, занимают здесь одно из центральных мест [3, с. 7]. К этой парадигме тяготеет современная линия исследований в русле «MemoryStudies» (П. Нора, Б. Гене, П. Хаттон, Дж. Спиннер-Халив, М. Хирш, Е. А. Ростовцев, Д. А. Сосницкий, А. Ореховский, О. В. Герасимов и др.). Вторая же парадигма исторической ответственности основана на ином подходе к переработке прошлого как опыта и связана с извлечением уроков и проективного опыта, отказа от субъективации вины, накладываемой на последующие поколения, которые не имеют отношения к прошлым историческим событиям. Присутствие проблематики вины здесь возникает исключительно благодаря интерсубъективности пространства дискурса об исторической ответственности без выстраивания бинарной оппозиции <правый-виноватый>, <преступник-жертва> или $<$ свой-чужой> [4, с. 89]. Здесь делается ставка на преодоление негативного опыта с целью недопущения его в будущем исключительно по моральным соображениям, на освобождение от груза коллективной вины не через наказание, а переживание и прощение через обращение к надвременным смыслам, поиску объединяющих начал и моральных значимостей. Здесь важнее именно нацеленность на будущее, в котором не должно повториться некое действие, выходящее за рамки установленной общезначимой аксиологической парадигмы. Это парадигма проективного действия, направленная на создание благополучного будущего глобального масштаба, поскольку, оставаясь на признании условного характера ценностей малых социальных групп, имеющих собственные интересы, мы увеличиваем поле будущих рисков и субъектов этих рисков. И каждая из этих парадигм по-своему обнаруживает ценности и смыслы, в отношении к которым действуют субъекты и акторы социальной действительности. Первая парадигма в своих аксиологических предпочтениях делает упор на оценку, в том числе моральную оценку, и имплицирует другие идеи в соответствии с ней, а вторая акцент на поиск смысла этой оценки и ее аксиологического содержания. Так складываются разные уровни конструирования и проявления аксиологического содержания исторической ответственности.

Между выделенными нами парадигмами, безусловно, существует устойчивая связь и взаимообусловленность. Следует сразу обозначить характер этой свя- 
зи не как противопоставление ценностей относительных и универсальных, устанавливаемых, с одной стороны, политическим или социально-историческими задачами, а с другой - моралью как таковой к ее стремлении к обнаружению общезначимых законов вне историко-политических заказов [5, с. 113]. Здесь речь идет о тех законах, которые не являются законами познания, простыми ментальными или социальными фактами, а относятся к иной сфере бытия. Именно на существовании таких законов базируется парадигма ответственности глобального характера вне ее политической ангажированности. Идея ответственности в ней уходит далеко вперед за пределы воспроизводства прошлого в настоящем, значительно расширяя историческое содержание ответственности. О такой ответственности в связке онтологии, аксиологии и этики говорили русские космисты [6] и о такого рода ответственности говорили и говорят ряд современных философов, как например, Г. Йонас, В. Хесле, А. Несс и др. Если первая парадигма существует благодаря силе многочисленных связей с прошлым и влияния фактов прошлого на настоящее (чем больше выстраивается таких связей, тем критичнее становится сама идея исторической ответственности), то вторая парадигма более ориентирована на установление автономности социальных объектов (здесь было бы уместно применение в качестве объяснительного подхода объектно-ориентированной теории Г. Хармана), оставляя возможности появлению устойчивых аксиологических структур. В частности, В. Хесле, делая попытку возврата к идее наличия идеальной сферы бытия ценностей и во многом перекликаясь с идеей ответственности Г. Йонаса, говорит о том, что существуют идеи, определяющие структуры реального мира. За идеей ответственности стоит подобное более глубокое содержание, которое имеет дело с иной рациональностью - не экономической или политической, а нравственной, прежде всего [7].

Определяя преемственность двух парадигм, можно отметить также их последовательное единство на основе развития идеи памяти. Память сохраняет не просто факт прошлого (он со временем забывается), а круг коннотаций, влияющий на новый опыт. С течением времени прошлое занимает все меньше и меньше места, но остается круг коннотаций, с которым приходится иметь дело изо дня в день. Можно просто хранить его, подпитывая память, а можно сделать его основанием рефлексивного сознания, определяя в нем описательное и нормативное содержание с точки зрения его практически позитивной возможности укрепления и использования нового опыта для нужд настоящего. Чем активнее и глубже такая нормативная работа, тем больше возможностей для сохранения и развития опыта в будущем. «Сознание не просто пассивно отражает мир, но инстинктивно выбирает из всей доступной и навязываемой ему информации ту, которая оптимально способствует его росту. Несмотря на все революции в росте сознания, только порождающий принцип гарантирует непрерывность, которая представляет собой нечто большее, чем непрерывная память о ряде отдельных событий», - отмечает В. Хесле, говоря об опыте прошлого для формирования идентичности, в том числе и коллективной [7, с. 116]. Память имеет ценность настолько, насколько она способна породить ценностный принцип для нового «я». Таким образом, идентичность оказывается тем элементом первой указанной нами парадигмы, когда идея исторического способна перейти в ценностное из- 
мерение и стать весьма устойчивым элементов второй, выделенной нами парадигмы.

В отношении коллективной идентичности в качестве процесса конструирования значений (свойство ценностей) речь идет о создании этоса как особого социального образования на основе совокупности опыта, извлеченного из сложившихся социально-исторических и культурных практик, а с другой стороны, как единой системы ценностных предпочтений, соединяющей в себе описательный и нормативный образы. Нравственность коренится не в одних лишь социальных явлениях, но в социальном «я». Поэтому идея исторической ответственности как дискурс об исторических фактах и субъектах прошлого дискурса способна воспроизводить ценностный характер той или иной социальности на основе отличия нынешнего ценностного характера одной культуры в сравнении в иными возможными и имевшими место системами ценностных предпочтений. Идея исторической реконструктивной памяти чрезвычайна важна в становлении этоса, т. к. запускает процесс формирования идентичности. Однако стабильная идентичность формируется, по мысли В. Хесле, только в случае посвященности поиску высших смыслов, но отнюдь не из недовольства жизнью. Для выхода из кризиса идентичности надо освободиться от чувства вины, абсурдной искусственной нормативности и обратиться к исследованию и обоснованию того, почему прошлый опыт не стал позитивным. Это путь к поиску новых смыслов и выход из угрожающей безысходности. Неспособность увидеть аксиологические принципы в опыте прошлого закрывает путь к дальнейшему социально-историческому и культурному развитию. Однако признание ценностей еще не гарантия их подлинности. История знала много примеров тому, как чей-то личный пример и вера оказывались настолько заразительны, что даже ложные ценности оказывались предпочтительнее всех других. Прошлый опыт как опыт противоборства с миром должен осмысливаться как путь постижения оптимальной меры и преодоления случившейся дисгармонии.

Еще один путь связи между различными парадигмами исторической ответственности согласован с поиском ценностных оснований, к которым прибегают практики наполнения исторической ответственности определенным ценностным содержанием. Речь идет о морали и политике и характере их взаимодействия в случае исторической ответственности. В. Хесле выступает против моральной оценки политики, однако отнюдь не освобождает последнюю от обязанности быть моральной. Для понимания аксиологии исторической ответственности это играет очень важную роль, поскольку все политические спекуляции на основе ответственности не имеют смысла, потому что в них нет моральной позитивности. Моральная позитивность предполагает не только отказ от практик прошлого, признаваемых преступными, но и от тех идей, которые были порождены этими практиками, например, практики неоправданного насилия во всех его формах. Идея воздаяния за имевшееся когда-то насилие может стать основой коллективной идентичности, но будет ли эта идея моральной? Вопрос ценностей здесь возникает сразу и бесповоротно - моральность обеспечивает ценность. Обратившись к анализу того, что сегодня признаем антиценностью (убийство, грабеж, притеснение и др.), исходя из прошлого опыта, для позитивной моральности мы 
должны декларировать отказ от воспроизводства подобных практик, неся историческую ответственность за их неповторение. При этом особое обоснование уже не требуется, т. к. оно уже эмпирически состоялось.

Превосходство или обособление политического от морального может привести к поиску более примитивных ценностей, существовавших до негативного прошлого опыта. И тогда все может повториться вновь или привести к пассивности и регрессии, когда идентичность может оказаться предпочтительнее нормативности, а также к непредсказуемости поведения политических институтов. Такое можно было наблюдать в Германии после Первой мировой войны и можно наблюдать сейчас в случае гражданских военных конфликтов повсеместно на почве политической переработки прошлого без рефлексии об аксиологических основаниях идей исторической ответственности. В качестве примера можно привести формы «справедливого реванша» движения лутеров в США сегодня. Результатами автономии политического в практике исторической ответственности может стать разрушение базовых социальных ценностей (например, доверия), перераспределение власти, всеобщий скептицизм - идеальные условия для возникновения новых исторических кризисов. Обращаясь к опыту прошлого, мы вдруг в один прекрасный момент понимаем, что все прошлые беды были связаны не с политикой как таковой, а с нашей ненасытностью в реализации амбиций, воплощенных в политике, - говорит В. Хесле. Чтобы это понять, нужно извлечь из прошлого уроки и прийти к разумной и позитивной самоидентификации как индивидуальной (себя как разумного существа) и коллективной. Коллективная самоидентичность связана с поиском ценностей не в политике или идеологии, а в выходе из них в стоящую над ними мораль, не подчиненную, а самостоятельную область определяющих ценностных смыслов.

Политика без морали - технология легитимного насилия, поэтому концепция исторической ответственности исключительно в политико-правовом поле как наказания лишь укрепляет власть. «Мудрость же состоит в том, что если обиды, травмы и кризисы идентичности, неотъемлемые от борьбы за признание, в конечном итоге приводят обе стороны к умиротворению зрелости, то они должны быть преданы забвению,» - делает вывод В. Хесле [7, с. 122]. Таким образом, аксиологические основания идеи исторической ответственности связаны не столько с политикой, сколько с моралью. С политикой же сама идея может быть аксиологически связана настолько, насколько в ней сохраняется моральноэтическое содержание. Ответственности как особого морального чувства нельзя добиться принуждением, но само моральное требует социального и политического [8, с. 55].

Именно расширение морального, поиск общезначимых смыслов и их распространение в общественной практике становятся новой перспективой развития идеи исторической ответственности как проводника ценностных смыслов. Здесь актуализируется все, что способно утвердить то, что прошло проверку историческим опытом - уважение к жизни, забота о мире и человеке, сам мир и гарантии мира с возможностью существования в нем с минимальными рисками. На первый план выходит идея глобальной экологии. Идея становится настолько значима (в том числе и ее теоретические конструкты), насколько она способна рабо- 
тать на перспективу и обладать проективной силой. В этом отношении историческая ответственность может стать вариантом глобальной ответственности в отношении будущего. Мир будущего представляется уже не миром этносов, наций, государств, классов и политических режимов - актуализация всеобщей экологии работает на историческую перспективу, перекрывая все остальное. На необходимость сознания этого факта указывают многие современные философы. В одном из своих последних интервью журналу «Phylosophy now» Грэхам Хapман справедливо замечает, что на первый план сейчас выходят иные насущные вопросы, нежели проблемы капитализма или антикапитализма, а проблемы окружающей среды по своей важности преобладают над всеми остальными, хотя и скрыты в тени иных проблем ${ }^{1}$. Это и есть новая аксиологическая перспектива проекции идеи исторической ответственности в будущее.

Вслед за ним другой философ современности А. Несс говорит прямо, что борьба за власть сейчас сосредоточена в борьбе за менталитет будущего [9]. Однако менталитет будущего далек от консьюмеризма, историко-политических амбиций, но должен ориентироваться на сохранение человеческого в человеке через понимание этого человеческого, весьма далекого от того, что мы можем получить, приобрести или выиграть как исторический или политический бонус. В первую очередь историческая ответственность должна ориентироваться на общество, достойное человека, где ценности предполагаются как идеально значимые, но и практически востребованные ориентиры, реконструированные из переживания и осмысления самых значимых исторических фактов.

Чаще всего самым опасным и острее всего переживаемым фактом негативного опыта социальности является насилие. Его крайние формы трудно предотвратить и пережить. Поэтому одним из ключевых принципов последующих ступеней социального развития на основе исторического опыта, когда происходит смена парадигм, меняющих не только социальный порядок, но и социальное сознание, становится ненасилие, приобретающее по мере расширения социальноисторического опыта все более глобальный контекст и статус самостоятельной ценности, предполагая ценность человека не только в его идеальном варианте, но и в многообразной повседневности. Война, например, не должна считаться достойным человека занятием, как и любые другие формы уничтожения человеком человека и других живых существ. В этой перспективе вопросы коллективного опыта выходят далеко за пределы ограниченных социальных общностей, где уже не будет иметь значение этническая принадлежность и даже идентичность. «То, что будет иметь значение - соблюдают ли эти люди правила, обращаются ли они друг с другом как со своим ближними, чувствуют ли они реальную и обязывающую их ответственность за жизнь на земле», — говорит А. Несс [9]. По мысли философа, все исторические эпохи пережили период, когда слова и значения возникали и угасали. Сейчас мы должны найти наши слова и значения будущего.

1 Интервью с профессором Г. Харманом // Phylosophy Now. Issue 139. August/September. 2020. 
Здесь ответственность лежит на средствах массовой информации и политиках, поскольку условия, ценности и наши нормы должны быть разъяснены. Таким образом, мы снова должны вернуться к поиску форм практического применения ценностных установок.

Исторический опыт на основе этического содержания и моральных уроков прошлого, оцененных в этических категориях, через поиск аксиологической составляющей создает гуманитарный и социокультурный капитал, который тем прочнее и жизнеспособнее, чем более общезначимого смысла в него заложено и чем более он ориентирован на передачу этого смысла в отношении будущего. Аксиологический контекст исторической ответственности существует не только как ценностный дискурс о прошлом, как конструирование этосов в настоящем, но и способ нахождения тех векторов дальнейшего развития, которые касаются будущего, не ограниченного пределами конкретной исторической и политической практики, но связываемого с завтрашним благополучием всего мира. Таким образом, за идеей исторической ответственности стоит определенная работающая система верифицированных историческим опытом значимостей такого же глобального масштаба как и сами исторические уроки.

\section{Литература}

1. Томильцева Д. А. Историческая и политическая ответственность: совпадение границ проблемного поля // Полития. 2016. № 4(83). С. 25-35.

2. Jonas H. Mortality and Morality: A Search for Good After Auschwitz. Evanston: Northwestern University Press, 1996. 218 p.

3. Вострецов Е., Симонова И. А. Историческая ответственность в полигенеративной среде: версии и инверсии практики // Педагогическое образование в России. 2015. № 5. C. 6-12.

4. Кривоносова Е. Э., Рудковский Э. И. Грани исторической ответственности // Ученые записки. 2017. Т. 24. С. 85-90.

5. Анисимов С. Ф. Введение в аксиологию. М.: Современные тетради, 2001. 28 с.

6. Авдеева И. А. Всеобщий характер моральной ответственности в философии русского космизма // Философия и общество. 2020. № 4. С. 51

7. Хесле В. Кризис индивидуальной и коллективной идентичности // Вопросы философии. 1994. № 10. С. 112-123.

8. Хесле В. Об отношении морали и политики // Полис. Политические исследования. 2013. Ч. І, № 4. С. 45-61.

9. Нэсс А., Мейляндер П. Менталитет будущего // Зеленый лист. 2013. № 3. С. $36-39$.

Статья поступила в редакиию 18.11.2020; одобрена после рецензирования 19.11.2020; принята к публикации 25.11.2020. 


\section{AXIOLOGICAL PARADIGMS OF HISTORICAL RESPONSIBILITY}

Irina A. Avdeeva

Cand. Sci. (Philos.), A/Prof., Senior Researcher,

A/Prof. of Ethics Department,

Lomonosov Moscow State University

27/4 Lomonosovsky Prospect, Moscow 119991, Russia

avdeeva@rambler.ru

Abstract. The article deals with the possible paradigms of the axiological content of historical responsibility. The first paradigm is associated with historical and political studies of the phenomenon of trauma and guilt and is aimed at political and legal practice. The second paradigm aims at developing the principles of the future as an object of historical responsibility. Both paradigms are interconnected and represent different sides of both action and research into the phenomenon of historical responsibility. The first arises on the basis of the second and is currently acquiring a global character, and generating new ideas. The first reconstructs values that are more situational and transitory, the second is aimed at finding more fundamental values. In particular, one of these ideas, which emerged on the basis of the idea of historical responsibility to future generations, is the environmental responsibility. According to a number of authors, this idea is of top priority now, and has a relevant social and ethical content.

Keywords: historical responsibility; ethics; values; environmental ethics; ethos; sociohistorical practice; socio-ethical experience. 